\title{
THE TEMPERATURE OF SOLID CARBONIC ACID AND ITS MIXTURES WITH ETHER AND ALCOHOL, AT DIFFERENT PRESSURES.
}

By John Zeleny and Anthony Zeleny.

1. Solid carbonic acid and more especially a mixture made by the addition of ether or alcohol have long been used for the maintenance of a fixed low temperature. Under reduced pressures the temperature of the substance is reduced still further, and a knowledge of the temperature assumed at any given pressure gives one the means of readily producing and maintaining temperatures between $-77^{\circ} \mathrm{C}$. and - I $15^{\circ} \mathrm{C}$. We are not aware that any detailed study of the variation of the temperature of the above mixtures with pressure has been made, although du Bois and Wills ${ }^{1}$ have obtained the temperature of the carbonic acid snow itself at several pressures.

There are differences of opinion among the different writers as to the effect of adding ether or alcohol to the carbonic acid snow, and the value of the temperature is usually given without any regard to the effect of changes in the barometric pressure. There is disagreement, too, among the values given for the temperature of the carbonic acid snow itself at atmospheric pressure.

Cailletet and Colardeau ${ }^{2}$ give $-60^{\circ} \mathrm{C}$. for the temperature of carbonic acid snow at atmospheric pressure, and $-76^{\circ} \mathrm{C}$. as the temperature in a good vacuum. For a mixture of carbonic acid and ether at atmospheric pressure they give the value $-77^{\circ} \mathrm{C}$., and for the temperature of the mixture in a good vacuum they give the value $-103^{\circ} \mathrm{C}$. For a mixture of carbonic acid and alcohol the value given by them is $-72^{\circ} \mathrm{C}$.

Regnault ${ }^{3}$ gives $-78^{\circ} .16$ for the boiling point of carbonic acid. Villard and Jarry ${ }^{4}$ give the temperature as $-79^{\circ} \mathrm{C}$. and state that

${ }^{1}$ Beibl. zu d. Annal. der Physik, 24, p. 428.

2 Jour. de Physique (2), 7, p. 430.

3 Ann. de Chim. et de Phys. (3), 26, p. 259.

4 Compt. Rend., 120 , p. I4I 3 . 
the variations due to the changes of the barometer are insignificant, although at a pressure of $5 \mathrm{~mm}$. they found the temperature of the snow to be $-125^{\circ} \mathrm{C}$. They state that at atmospheric pressure no change in the temperature was produced by adding ether to the snow.

Du Bois and Wills ${ }^{1}$ give the temperature of carbonic acid snow at atmospheric pressure as $-79^{\circ} .2 \mathrm{C}$., with a rate of change of $\mathrm{I}^{\circ} \mathrm{C}$. for a change of $55 \mathrm{~mm}$. in the pressure.

For the temperature of a mixture of ether and carbonic acid snow Travers ${ }^{1}$ ascribes to Olzewski the value of $-78^{\circ} .2 \mathrm{C}$. Witkowski ${ }^{2}$ gives $-78^{\circ} .5 \mathrm{C}$. for the same mixture. Holborn ${ }^{3}$ found the temperature of a mixture of absolute alcohol and carbonic acid snow at atmospheric pressure to be $-78^{\circ} .34 \mathrm{C}$, with a variation of $0^{\circ} .20$ for a change of $\mathrm{I} \mathrm{cm}$. in the pressure. Carbonic acid snow itself gave a temperature $0^{\circ}$. Io C. lower.

2. In the experiments here described the carbonic acid snow was obtained from a cylinder of commercial liquid carbonic acid. The temperatures were measured by means of a nickel-iron thermoelectric couple. This was calibrated by the use of six known temperatures. The two temperatures used upon which the values given in this paper mainly depend are: $(a)$ the value given above which Holborn obtained with a hydrogen thermometer for the temperature of a mixture of absolute alcohol and carbonic acid snow, and, (b) the temperature of boiling ethylene which was taken as $-103^{\circ} .9$ C. for a pressure of $74.0 \mathrm{~cm} .{ }^{4}$ The measurements were made with a D'Arsonval galvanometer which, with the scale at a distance of 2.6 meters, enabled the temperature to be read to $\mathrm{O}^{\circ}$.or $\mathrm{C}$. The couple was short-circuited after each deflection and the reading taken so as to eliminate the errors due to any thermo-electric forces in other parts of the circuit. Errors due to either a set in the fiber or to hysteresis ${ }^{5}$ were eliminated at the same time. The changes in the room temperature were too slight to necessitate any correction for temperature.

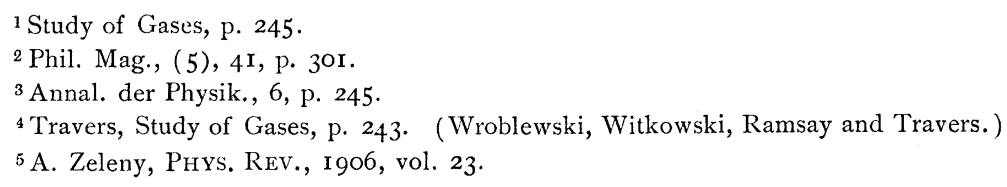


3. (a) Attention was first directed to the temperature of carbonic acid snow contained in an open vessel. It is known ${ }^{1}$ that to maintain a constant temperature the snow must be surrounded by its own vapor. A glass beaker was nearly filled with the snow and the thermo-electric junction was placed in its center.

As long as the windows of the room were closed and the air was well at rest the temperature of the snow in the beaker remained quite constant at its normal value, but the presence of any draughts at once lowered the temperature appreciably. Blowing past the beaker with a bellows and thus rapidly removing the vapor caused the temperature to decrease by over $\mathrm{I} 5^{\circ} \mathrm{C}$.

A piece of the snow placed over the junction and held above the table so that the vapor formed could flow downward from the solid had its temperature reduced by over $10^{\circ} \mathrm{C}$. below the normal temperature.

A deep vessel only partly filled with the snow and preferably corked so as to leave but a small vent, answers best for maintaining a constant temperature. The snow must however be well packed so as to make a good contact with the junction or else a slightly too high temperature is obtained. On the other hand the stirring caused by the act of packing down the snow seems to increase the rate of evaporation and causes a small temporary diminution of the temperature.

(b) In the next place a mixture made of ethyl ether and carbonic acid snow was placed into the glass beaker. The temperature of this remained very constant, unaffected by slight draughts; and the blowing of a strong blast with a bellows by the mixture barely diminished its temperature by $0^{\circ} .02 \mathrm{C}$. It seems that the heat received from the air blast almost exactly equalized the cooling due to the more rapid evaporation caused by the removal of the vapor. After the blowing had been continued for some time, however, the uppermost parts of the surface became whitish as if the ether had all evaporated from them and exposed the clear snow. When this point was reached the evaporation was accelerated and the mixture began to cool just as it had done in the case of the dry snow; and by continuing the blowing the temperature of the whole was reduced by several degrees.

1 Faraday, Phil. Trans., I845, p. I55. DuBois and Wills, loc. cit. 
Under normal conditions however the temperature of the ether mixture is remarkably constant, ${ }^{1}$ as long as the snow is moist and as long as the:e is not enough ether present for a liquid surface to form over the snow.

Stirring the mixture had a tendency to produce a temporary lowering of the temperature by about $0^{\circ} .02 \mathrm{C}$. When the mixture is first made a temporary lowering of the temperature by as much as $0^{\circ} .5 \mathrm{C}$. was observed. This always disappears soon, however, and may be due to some of the snow dissolving in the ether.

(c) A mixture was next made of absolute alcohol and the carbonic acid snow, and placed into the glass beaker. To assume its lowest temperature this mixture must be quite thick, much more so than is necessary with the ether mixture. There should be no appearance of any free liquid throughout the mass of the mixture. Blowing a strong blast of air past the mixture with the bellows caused a rise in temperature of about $0^{\circ} .2 \mathrm{C}$. The cooling due to the increased rate of evaporation at the surface is not sufficient in this case to equalize the heat received from the air blast. An increased ebullition in the interior of the mass however prevents the temperature from rising very far. When the blast was continued, the heat from it vaporized so much of the carbonic acid in a short time, that the mass became too moist from an excess of the alcohol, the ebullition became very brisk and the temperature increased quite rapidly.

$(d)$ It thus appears that of the three refrigerants, dry carbonic acid snow, a mixture of absolute alcohol and carbonic acid snow, and a mixture of ether and carbonic acid snow, the last is the best one to use for maintaining a uniform temperature. The absolute temperature of the three, however, was found to be identical when they were placed in a deep vessel so as to be surrounded by their own vapor. The differences which were observed for the three at different times for the same barometric pressure did not exceed $0^{\circ} .02 \mathrm{C}$.

4. The temperature of the three refrigerants was next measured when they were subjected to different pressures. In some cases

1 We could not observe any change of temperature when a vessel with the mixture was covered to exclude air, such as is described by Faraday (loc. cit.). 
the substance was placed in a long cylindrical Dewar flask $4 \mathrm{~cm}$. in diameter. The opening was closed with a rubber stopper through which the thermo-electric couple passed and from which a rubber tube led to an open mercury manometer and to a water pump. A vessel of large volume was placed in series so as to equalize some of the variations due to the inconstancy of the pump. In other cases the Dewar vessel was replaced by a glass tube of the same diameter. The advantage of this was that it could be placed inside of a large Dewar cylinder to protect it from heat but when the temperature was to be raised the tube could be withdrawn and the process greatly accelerated.

To produce pressures higher than an atmosphere the rubber tube leading from the containing vessel was partly closed by means of a screw clamp. Also in adjusting for the lower pressures the rubber tube leading from the vessel was closed by the proper amount with the screw clamp, while the water pump was operated at a constant pressure. By watching the indications of the manometer and carefully using this screw the variations of the pressure could readily be kept within a millimeter.

The temperature of the refrigerant assumes its final value much more rapidly in going from a higher to a lower temperature than in the reverse direction. In the first case the rapid evaporation quickly cools the mixture to its final temperature while in the second case the heat has to come in through the walls of the vessel. It is especially desirable, therefore, when a Dewar cylinder is used, to approach any temperature from one that is higher. With the protection of the Dewar flask the freezing mixtures evaporate but slowly even at low pressures and so any temperature can be maintained for a long time without a change of material.

5. Eight sets of readings with over a hundred observations were taken with the three refrigerants. The reduced values that were obtained were plotted on a large scale and the points for the three substances all appeared to belong to one and the same curve. It was concluded that the temperatures of the three substances at any one pressure are the same. A single curve was therefore drawn through all of the points obtained. The agreement of the observations was on the whole good although a few of the individual points 
varied as much as $\mathrm{O}^{\circ} .5$ from the main curve. The observations with the alcohol mixture did not extend below $-100^{\circ} \mathrm{C}$.

The values of the temperatures at the different pressures was read off from the curve thus obtained and the results are given in the following table:

The Temperature of Carbonic Acid Snow and Its Mixtures with Ether and Alcohol, at Different Pressures.

\begin{tabular}{|c|c|c|c|}
\hline $\begin{array}{l}\text { Pressure in } \\
\text { Centimeters } \\
\text { of Mercury. }\end{array}$ & $\begin{array}{l}\text { Temperature. } \\
\text { OC. }\end{array}$ & $\begin{array}{l}\text { Pressure in } \\
\text { Centimeters } \\
\text { of Mercury. }\end{array}$ & $\begin{array}{c}\text { Temperature } \\
\text { OC. }\end{array}$ \\
\hline 2 & -116.7 & 44 & -85.2 \\
\hline 3 & -112.9 & 46 & -84.6 \\
\hline 4 & -110.0 & 48 & -84.1 \\
\hline 5 & -107.8 & 50 & -83.6 \\
\hline 6 & -106.0 & 52 & -83.1 \\
\hline 7 & -104.5 & 54 & -82.6 \\
\hline 8 & -103.2 & 56 & -82.2 \\
\hline 9 & -102.1 & 58 & -81.8 \\
\hline 10 & -101.1 & 60 & -81.4 \\
\hline 12 & -99.4 & 62 & -80.9 \\
\hline 14 & -97.9 & 64 & -80.5 \\
\hline 16 & -96.5 & 66 & -80.1 \\
\hline 18 & -95.3 & 68 & -79.76 \\
\hline 20 & -94.2 & 70 & -79.40 \\
\hline 22 & -93.2 & 72 & -79.04 \\
\hline 24 & -92.2 & 73 & -78.86 \\
\hline 26 & -91.3 & 74 & -78.68 \\
\hline 28 & -90.5 & 75 & -78.51 \\
\hline 30 & -89.7 & 76 & -78.34 \\
\hline 32 & -89.0 & 77 & -78.17 \\
\hline 34 & -88.3 & 78 & -78.00 \\
\hline 36 & -87.7 & 80 & -77.66 \\
\hline 38 & -87.0 & 82 & -77.33 \\
\hline 40 & -86.4 & 84 & -77.00 \\
\hline 42 & -85.8 & & \\
\hline
\end{tabular}

It is seen that at atmospheric pressure the temperature of the mixtures changes by $0^{\circ} .17 \mathrm{C}$. for a change of $\mathrm{I} \mathrm{cm}$. in the pressure. This rate increases as the pressure is diminished so that at a pressure of $2 \mathrm{~cm}$. it is over twenty times as large.

The values given by du Bois and Wills (loc. cit.) for the temperature of carbonic acid snow are from $1^{\circ}$ to $2^{\circ}$ lower than those 
determined by us for the snow and its mixtures with ether and alcohol. Thus at $76 \mathrm{~cm}$. pressure their value is $-79^{\circ} .2 \mathrm{C}$. and at $4 \mathrm{~cm}$. pressure, $-\operatorname{II} 2^{\circ} \mathrm{C}$. The differences appear to be due to the fundamental temperatures assumed for the calibration of the thermo-electric couples.

Physical Laboratory, The University of Minnesota.

June 29, r 906. 